\title{
Susceptibility to Type 1 (insulin-dependent) diabetes mellitus in Spanish patients correlates quantitatively with expression of HLA-DQ $\alpha$ Arg 52 and HLA-DQ $\beta$ non-Asp 57 alleles
}

\author{
M.D. Gutierrez-Lopez ${ }^{1}$, S. Bertera ${ }^{2}$, M.T.Chantres ${ }^{1}$, C. Vavassori ${ }^{2}$, J.S.Dorman ${ }^{3}$, M. Trucco ${ }^{2}$ and M.Serrano-Rios $^{1}$ \\ ${ }^{1}$ Hospital Clinico San Carlos, Universidad Complutense, Madrid, Spain; ${ }^{2}$ Department of Pediatrics, Division of Immunogenetics, \\ University of Pittsburgh, Rangos Research Center, Children's Hospital of Pittsburgh and ${ }^{3}$ Department of Epidemiology, \\ Graduate School of Public Health, University of Pittsburgh, Pittsburgh, Pennsylvania, USA
}

Summary. HLA-DQ $\alpha$ and $\beta$ alleles were chosen as the most sensitive Type 1 (insulin-dependent) diabetes mellitus susceptibility markers for evaluating the disease associations and Type 1 diabetes risk in a population-based registry from Madrid. The absence of aspartic acid in position 57 of the DQ $\beta$ chain (non-Asp 57), and the presence of arginine in position 52 of the DQ $\alpha$ chain $(\operatorname{Arg} 52)$ were found to be reliable markers of Type 1 diabetes susceptibility among the Spanish population, with significantly higher frequencies among the cases of Type 1 diabetes compared to randomly selected nondiabetic control subjects from the general Madrid population. While non-Asp 57 homozygosity conferred an absolute risk of 32.3 per 100,000 per year and Arg 52 of 31.5 per
100,000 per year, the risk for double homozygotes for both non-Asp 57 and Arg 52 was estimated as 101.7 per 100,000 per year. Individuals homozygous for only one of these alleles, and heterozygous at the other locus, had a markedly lower Type 1 diabetes risk (12.8 per 100,000 per year), approximating the general population incidence for Madrid. Thus, susceptibility to Type 1 diabetes in Spanish patients is associated, quantitatively, with non-Asp 57 DQ $\beta$ and Arg 52 $\mathrm{DQ} \alpha$ alleles.

Key words: Type 1 (insulin-dependent) diabetes mellitus, HLA-DQ $\alpha$, Arg 52, HLA-DQ $\beta$ non-Asp 57, Spain.
The completion of registries for Type 1 (insulin-dependent) diabetes mellitus in numerous countries has revealed striking geographic differences in the incidence of the disease $[1-3]$. This variation is particularly evident when comparing populations from Northern Europe with those from Asian countries [1]. For example, a child in Finland has an estimated risk for developing Type 1 diabetes which is almost 40 times greater than a child in Japan, China or Korea. The age-adjusted incidence rate in this Scandinavian country is $\approx 30$ per 100,000 per year [3], while the rate is less than 1 per 100,000 per year in Japan [1]. Even among Caucasians, there is distinct variability in the annual incidence of the disease. Rates are much lower in Central and Southern Europe (e.g., France: 7 per 100,000 per year [4]; Northern Italy: $4-10$ per 100,000 per year [5-7]) than in Northern Europe (Norway: 20.5 per 100,000 per year [8]; Sweden: 23.6 per 100,000 per year [9]). These data provided the basis for speculating that a north-to-south incidence gradient exists in which environmental factors, such as viruses $[10,11]$, nutrition $[12,13]$ or other life-style habits [14-16] are contributing to the world-wide patterns of Type 1 diabetes [1-3].

This idea was recently challenged by data from Sardinia and Spain, where the annual Type 1 diabetes incidence rates are 32 per 100,000 [17], and 11.3 per 100,000 per year
[18], respectively, despite being on similar latitudes. A possible explanation for this remarkable difference was found in the unusual genetic features of the Sardinian population [19], which was recently emphasized by two independent research groups $[17,20,21]$. A study of five populations also suggests that the variation in the frequency of Type 1 diabetes susceptibility genes across populations is reflected by Type 1 diabetes incidence rates [22].

It has recently been shown that the absence of aspartic acid in position 57 of the $\mathrm{DQ} \beta$ chain (non-Asp 57) is positively associated to Type 1 diabetes [23-25], and that the influence of this marker is even more dramatic when the typing of the DQ $\alpha$ chain is also considered $[26,27]$. In the current report, the frequency of HLA-DQ $\alpha$ and $\beta$ alleles, ascertained from randomly selected cases from the $\mathrm{Ma}$ drid Type 1 diabetes registry and unrelated non-diabetic control subjects from the general population at risk, was determined.

\section{Subjects and methods}

For this investigation, 102 diabetic patients were randomly selected, according to standardized methods, from those identified by the Madrid Type 1 diabetes registry. All Type 1 diabetic patients were on in- 
Table 1. HLA-DQB1 and DQA1 gene frequencies in Type 1 (insulin-dependent) diabetic patients and unrelated non-diabetic controls subjects

\begin{tabular}{|c|c|c|c|c|c|}
\hline \multirow[t]{3}{*}{ Molecular allele } & \multicolumn{4}{|c|}{ Madrid population } & \multirow{3}{*}{$\begin{array}{l}\text { Caucasi- } \\
\text { an popu- } \\
\text { lations }^{\mathrm{a}} \\
\text { Freq. }\end{array}$} \\
\hline & \multicolumn{2}{|c|}{$\begin{array}{l}\text { diabetic } \\
(n=102)\end{array}$} & \multicolumn{2}{|c|}{$\begin{array}{l}\text { Non-diabetic } \\
(n=87)\end{array}$} & \\
\hline & $n$ & Freq. & $n$ & Freq. & \\
\hline DQB $1 * 0501(n D)$ & 11 & 0.05 & 37 & 0.22 & 0.11 \\
\hline DQB1 $* 0602^{b}(\mathrm{D})$ & 0 & 0.00 & 34 & 0.19 & 0.16 \\
\hline DQB1*05031 (D) & 2 & 0.01 & 0 & 0.00 & 0.02 \\
\hline DQB $1 * 0502(\mathrm{nD})$ & 4 & 0.02 & 0 & 0.00 & 0.01 \\
\hline DQB $1 * 0201(\mathrm{nD})$ & 112 & 0.55 & 38 & 0.22 & 0.25 \\
\hline DQB1*0301 (D) & 16 & 0.08 & 28 & 0.16 & 0.22 \\
\hline DQB1*0302(nD) & 53 & 0.26 & 20 & 0.11 & 0.11 \\
\hline DQB1*03032 (D) & 6 & 0.03 & 14 & 0.08 & 0.02 \\
\hline DQB1 $* 0402(\mathrm{D})$ & 0 & 0.00 & 3 & 0.02 & 0.10 \\
\hline $\begin{array}{l}\text { DQA1*0101 (nR) } \\
\text { DQA1*0102 } \\
\text { DQA1*0103 }\end{array}$ & 19 & 0.09 & 66 & 0.38 & - \\
\hline DQA1*0201 (nR) & 5 & 0.02 & 24 & 0.14 & - \\
\hline DQA1*0301 (R) & 69 & 0.34 & 29 & 0.17 & - \\
\hline DQA1*0401 (R) & 111 & 0.55 & 55 & 0.31 & - \\
\hline \multicolumn{6}{|l|}{ DQA $1 * 0501$} \\
\hline DQA $1 * 0601$ & & & & & \\
\hline
\end{tabular}

D, Asp 57; nD, non-Asp 57; R, Arg 52; nR, non-Arg 52. ${ }^{\text {a }}$ The percentages are average values deduced from the literature [21]. ${ }^{\mathrm{b}}$ The oligonucleotide used to type for DQB1*0602 also recognized the very similar allele DQB $1 * 0603$

sulin therapy at hospital discharge, less than 15 years of age and residents of Madrid at the time of onset of the disease, between 1 December 1985 and 1 December 1988 [18]. Fifty-seven were male, 45 were female; their mean current age was 14 years (range: $3-25$ years).

Eighty-seven control subjects, with no history of Type 1 diabetes, were randomly selected from the same geographical area, according to a standardized protocol [22]. This sampling procedure permitted the identification of non-diabetic control subjects with the same age and sex distribution as the population at-risk for the time period covered by the registry. Their mean current age was 16 year (range: 5-29 years). Forty were male and 47 were female. The epidemiologic procedures developed for selecting Type 1 diabetic patients and non-diabetic control subjects are those currently employed for the WHO Multinational Project for Childhood Diabetes [28].

Peripheral blood lymphocytes (PBL) from all donors were used for the molecular typing of the most common HLA-DQ $\alpha$ and $\beta$ chain gene allelic forms [29]. To this aim, DNA was extracted from each individual's PBL using standard techniques [30]. The genomic DNA was subjected to polymerase chain reaction (PCR) amplification [31] of the second exon of the DQ $\alpha$ and $\beta$ chain genes, each encoding the most polymorphic, first external domain of their respective chains, as previously described $[21,24,32]$. The procedure was carried out using for the $\mathrm{DQ} \beta$ typing the following primers for amplification: P2: 5'-GATTTCGTGTACCAGTTTA AGG-3' and Pw4: 5'-CTCGTAGTTGTGTCTGGCACAC-3'. For DQ $\alpha$ typing instead we used primers P7: $5^{\prime}$-GTGCTGCAGGTGTAAACTTGTACCAG-3'; and P8: 5'-CACGGATCCGGTAGCAGCGGTAGAGTTG-3'. Successful PCR amplifications were obtained from each individual's genomic DNA using the thermostable Taq polymerase and a Thermocycler from Perkin Elmer Cetus (Norwalk, CT, USA). After 30 cycles of amplification, $0.5 \mu \mathrm{g}$ of DNA yielded a product of 237 base pairs (bp) for the DQ $\beta$ gene and a product of 242 bp for the DQ $\alpha$ gene. Dot blot analysis was carried out using $16 \%$ of either the $\alpha$ or $\beta$ amplified material from each individual, diluted in $0.4 \mathrm{~mol} / 1 \mathrm{NaOH}, 25 \mathrm{mmol} / \mathrm{l}$ EDTA and applied to $\mathrm{Ny}$ - tran membranes (Schleicher and Scheull, Keene, NH, USA) using a Biodot apparatus (BioRad, Rockville Centre, NY, USA). The DNA was crosslinked to the membrane by ultraviolet irradiation and prehybridized at $42^{\circ} \mathrm{C}$. The blots were probed at $42^{\circ} \mathrm{C}$ overnight with allele specific oligonucleotide probes. The filters were then washed with $6 \times \mathrm{SSC} \quad\left(1 \times \mathrm{SSC}=0.15 \mathrm{~mol} \cdot 1^{-1} \mathrm{NaCl}, \quad 0.015 \mathrm{~mol} \cdot 1^{-1} \mathrm{Na}\right.$ citrate) $0.1 \%$ sodium dodecyl sulphate (SDS) at the temperatures indicated below to remove any probe that had one or more mismatches with the target sequence. The following oligonucleotide probes were used to identify $\mathrm{DQ} \beta$ specific alleles:

DQB1*0302: 5'-GGCCGCCTGCCGCCGAG-3' (Amino Acid (AA) 54-59) at $65^{\circ} \mathrm{C}$,

DQB1*0301: 5'-GGCCGCCTGACGCCGAG-3' (AA 54-59) at $66^{\circ} \mathrm{C}$

DQB1*0501: 5'-GGCGGCCTGTTGCCGAG-3' (AA 54-59) at $62^{\circ} \mathrm{C}$

DQB1*0602: 5'-GGCGGCCTGTTGCCGAG-3' (AA 54-59) at $62^{\circ} \mathrm{C}$,

DQB1*0502: 5 -GGCGGCCCAGCGCCGAG-3* (AA 54-59) at $62^{\circ} \mathrm{C}$,

DQB1*05031: 5'-GGCGGCCTGACGCCGAG-3' (AA 54-59) at $62^{\circ} \mathrm{C}$,

DQB1*0201: 5'-GCTGGGGCTGCCTG-3' (AA 52-58) at $62^{\circ} \mathrm{C}$, and

DQB1*0402: 5'-GGCGGCCCTTGACGCCGAG-3' (AA 54-59) at $60^{\circ} \mathrm{C}$.

To better distinguish DQB $1 * 0301$ from 0302 and 03032 , which frequently cross-hybridize, the use of an additional probe specific for DQB1*0301 around AA 26 was necessary: DQB1*0301-26: 5'CGTGCGTTATGTGACCA-3' (AA 23-29) at 52 ${ }^{\circ} \mathrm{C}$. When doubts were still present, our "digestion" method [32] was used to establish the correct typing.

DQ $\alpha$ typing was performed in the same manner except that the following allele specific oligonucleotides were used as radiolabelled probes to identify the specific alleles: DQA1*0101, 0102, 0103: 5'-TCAGCAAATTTGGAGGTT-3' (AA 51-57) at $50^{\circ} \mathrm{C}$; DQA $1 * 0201: 5^{\prime}$-TCCACAGACTTAGATTTG-3' (AA 51-58) at 50 ${ }^{\circ} \mathrm{C}$; DQA $1 * 03011, \quad 03012$, 0302: 5'-TCCGCAGATTTAGAAGAT-3' (AA 51-57) at $50^{\circ} \mathrm{C}$; DQA1*0401, 05011, 05012, 05013, 0601: 5'-TCAGACAATTTAGATTTG-3' (AA 51-58) at $46^{\circ} \mathrm{C}$; DQA $1 * 05011,05012$, 05013: 5'-CTTGAACAGTCTGATTAA-3' (AA $72-78$ ) at $48^{\circ} \mathrm{C}$.

The nomenclature used to define the tested HLA genes was according to the official Nomenclature for Factors of the HLA System 1991 [33].

\section{Statistical analysis}

The gene frequencies were obtained by counting the total number of specific DQ $\alpha$ and $\beta$ chain gene allelic forms, as defined by oligoprobe analysis, for the diabetic and non-diabetic individuals. $\chi^{2}$ values were calculated using the Yates correction. When the expected frequency in one of the four cells of the $2 \times 2$ tables was less than 5, the Fisher exact test was used instead. All the $p$ values were corrected for multiple comparisons. Estimates of the relative risk (RR) associated with particular DQ alleles in the different individuals were calculated using Woolf's method, as modified by Haldane for small sample sizes when appropriate [34]. Genotype-specific incidence rates were calculated, as previously described, by expressing the overall incidence of Type 1 diabetes in a given population as a weighted average of the genotype-specific rates and the proportions of the populations exhibiting each genotype [22].

\section{Results}

The frequencies for all the DQB1 alleles identified in the Type 1 diabetes cases and non-diabetic control subjects from Madrid are shown in Table 1. DQB1*0501 and 0602 
Table 2. Relative and absolute Type 1 (insulin-dependent) diabetes risk estimates for HLA DQ $\alpha$ and $\beta$ genotype for the Madrid population

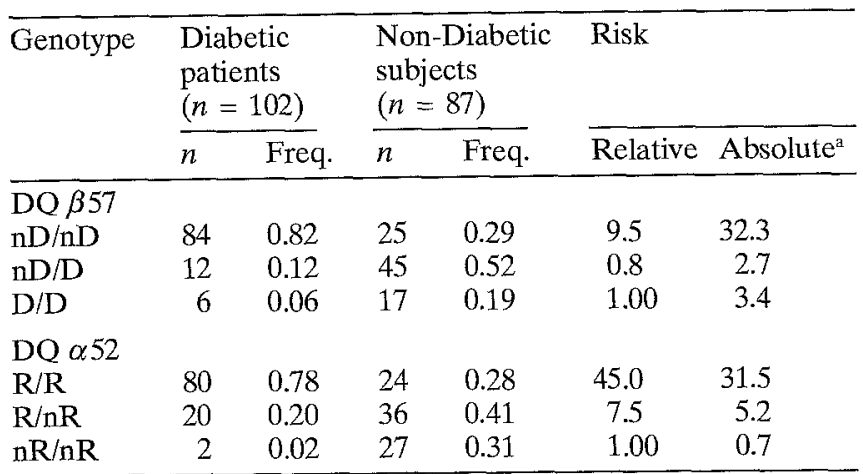

a $\times 100,000$ per year. The overall age-adjusted Type 1 diabetes incidence for Madrid is 11.3 per 100,000 per year

Table 3. HLA-DQ $\beta$ and DQ $\alpha$ chain combinations present in Type 1 diabetic patients and control subjects

\begin{tabular}{|c|c|c|c|c|c|c|c|c|c|c|}
\hline & \multicolumn{10}{|c|}{ DQA1 alleles } \\
\hline & $1 / 1$ & $1 / 2$ & 13 & 14 & $2 / 2$ & $2[3$ & $2 \sqrt{4}$ & \begin{tabular}{|l|l|}
3 & 3 \\
\end{tabular} & $3 \sqrt{3}$ & \begin{tabular}{|l|l|}
4 & 4 \\
\end{tabular} \\
\hline \begin{tabular}{|l|l|}
0201 & 0201 \\
\end{tabular} & & & & $4 /-$ & $1 /-$ & $1 / 1$ & $1 / 1$ & & $7 /-$ & $22 /-$ \\
\hline $\begin{array}{ll}0201 & 0301 \\
\end{array}$ & & & & & & & $-/ 2$ & $-/ 1$ & & $2 / 3$ \\
\hline 02010302 & & & & & & -12 & & $2 / 1$ & $26 /-$ & $-/ 1$ \\
\hline $\begin{array}{ll}0201 & 0303 \\
\end{array}$ & & & & & $-/ 2$ & & & & $2 / 1$ & $-/ 1$ \\
\hline 02010402 & $-/ 1$ & & & & & & & & & \\
\hline \begin{tabular}{|l|l|}
0201 & 0501 \\
\end{tabular} & -12 & $-/ 1$ & & $4 / 3$ & & & $-/ 1$ & & & $2 / 1$ \\
\hline \begin{tabular}{|l|l|}
0201 & 0502 \\
\end{tabular} & & & & $2 /-$ & & & & & & \\
\hline 02010602 & $-/ 1$ & -15 & & $-/ 4$ & $-/ 1$ & & & & & \\
\hline $0301 / 0301$ & & & $1 /-$ & $-/ 1$ & & $1 /-$ & & & $1 / 2$ & $-/ 2$ \\
\hline 03010302 & & & & & & & & $1 /-$ & $4 / 3$ & \\
\hline $0301 / 0303$ & & & & $-/ 1$ & & & & & $1 /-$ & $1 /-$ \\
\hline 03010501 & & & & $-/ 4$ & & & & & & \\
\hline $0301 / 0503$ & & & & $1 /-$ & & & & & & \\
\hline $0301 / 0602$ & & & & -12 & & $-/ 1$ & & & & $-/ 1$ \\
\hline 03020302 & & & & & & & & $5 / \sim$ & $2 / 2$ & \\
\hline 0302,0303 & & & & & & & & $2 / 1$ & & \\
\hline 03020402 & & & $-/ 1$ & & & & & & & \\
\hline 03020501 & & & $3 / 1$ & & & & & $-/ 1$ & & \\
\hline 03020503 & & & & $1 /-$ & & & & & & \\
\hline $\begin{array}{lll}0302 & 0602\end{array}$ & & & -14 & & & & & $-/ 1$ & & \\
\hline $0303 / 0303$ & & & & $-/ 1$ & $-/ 1$ & $-/ 1$ & & & & \\
\hline 03030501 & & & & & & & & & & $-/ 1$ \\
\hline $0303 / 0602$ & & & & & & & & & & $-/ 1$ \\
\hline $0402 / 0602$ & & & & $-/ 1$ & & & & & & \\
\hline \begin{tabular}{|l|l|}
0501 & 0501 \\
\end{tabular} & -17 & & & $1 /-$ & & & & & & \\
\hline $\begin{array}{lll}0501 & 0602 \\
\end{array}$ & -15 & -11 & & -12 & & & & & & \\
\hline \begin{tabular}{|l|l|}
0502 & 0502 \\
\end{tabular} & $1 /-$ & & & & & & & & & \\
\hline $0602 / 0602$ & & & & $-/ 2$ & & & & & & \\
\hline
\end{tabular}

Within each cell, the numbers listed represent diabetic patients/control subjects. Notation for DQA1 alleles is described in Table 1. Non-Asp 57 and Arg 52 alleles are in boxes

alleles in the studied population were found to be somewhat higher, and DQB $1 * 0201,0301$ and 0402 were lower than expected when compared to those for Caucasian populations [21]. Statistically significant increases in the frequencies of the non-Asp 57 DQB1*0201 and 0302 alleles among the diabetic compared to the non-diabetic subjects confirmed that these are the most common "diabetogenic" alleles among the Spanish population. On the contrary, the frequency of the Asp 57 DQB $1 * 0602$ allele was significantly decreased among the diabetic patients $\left(\chi^{2}=41.3, p<0.001\right)$, illustrating that this allele was strongly protective against Type 1 diabetes. Interestingly, the low prevalence of the DQB $1 * 0501$ allele among the diabetic patients vs control subjects $\left(\chi^{2}=21.0, p<0.001\right)$ seemed to suggest that this non-Asp 57 allele is not diabetogenic, at least in this Spanish population.

Relative and absolute risks were estimated for nonAsp 57 homozygotes, heterozygotes and Asp 57 homozygotes by combining all Asp 57 positive and negative alleles, respectively (Table 2). Relative to Asp 57 homozygotes, non-Asp 57 homozygotes had more than a nine-fold increase in Type 1 diabetes risk $(p<0.001)$, with an absolute risk estimate which was three times greater than the annual Type 1 diabetes incidence rate for the general Madrid population. In contrast, the absolute risk for heterozygotes and Asp 57 homozygotes was similar and quite low.

To evaluate the distribution of the DQA1 alleles (Table 1), the frequencies were calculated for only four groups, so defined, to allow a precise distinction between Arg 52 negative (DQA $1 * 0101,0102,0103$, and 0201) and Arg 52 positive (DQA1*0301, 0401, 0501, and 0601) alleles. Comparisons of the frequencies of each of the four groups of alleles between diabetic and non-diabetic individuals revealed that they were statistically different $(p<0.001)$. Eighty-nine percent of the alleles found in the diabetic individuals were Arg 52 positive.

Relative to non-Arg 52 homozygotes, $\operatorname{Arg} 52$ homozygotes were 45 times more likely to develop Type 1 diabetes $(p<0.01)$ and heterozygotes had a 7.5 -fold increase in risk $(p<0.01)$ (Table 2$)$. The absolute risk for Arg 52 homozygotes was similar to that for non-Asp 57 homozygotes.

Sixty-five percent of the Type 1 diabetic individuals were homozygous for both $\mathrm{DQ} \beta$ non-Asp 57 and $\mathrm{DQ} \alpha$ Arg 52 alleles, with the major components being DQB $1 * 0201 / 0302$ and DQA1 group 3/4, DQB $1 * 0201 /$ 0201 and DQA1 group 4/4, and DQB $1 * 0201 / 0201$ and DQA1 group 3/4 (Tables 3 and 4). Twenty-six percent of the diabetic patients were heterozygous at one or two of the loci considered, but carried at least one $\mathrm{DQ} \beta$ nonAsp 57 and one DQ $\alpha$ Arg 52 allele. Only $8 \%$ were missing either both DQ $\beta$ non-Asp 57 alleles (six individuals) or both DQ $\alpha$ Arg 52 alleles (two individuals). Thus, $92 \%$ of the diabetic patients carried at least one copy of the $\mathrm{DQ} \beta$ non-Asp57 and DQ $\alpha$ Arg 52 allele that can make a "diabetogenic" heterodimer either in cis or in trans associations. In the control population, however, only six individuals of the $87(7 \%)$ were homozygous for both $\mathrm{DQ} \beta$ non-Asp 57 and DQ $\alpha$ Arg 52 alleles, 38 (44\%) were heterozygotes at least at one of the two loci, and $43(49 \%)$ were missing either both $\mathrm{DQ} \beta$ non-Asp 57 alleles or both DQ $\alpha$ Arg 52 alleles.

Relative risks for various $\mathrm{DQ} \beta$ and $\mathrm{DQ} \alpha$ genotypes were first calculated by comparing each possible combination with the Asp 57 homozygous and non-Arg 52 homozygous group, which are likely to be least susceptible to Type 1 diabetes (Table 4). Individuals with both $\mathrm{DQ} \beta$ 
Table 4. Relative and absolute Type 1 (insulin-dependent) diabetes risk estimates of HLA-DQ $\alpha$ and $\beta$ genotypes and different "diabetogenic" heterodimers for the Madrid population

\begin{tabular}{|c|c|c|c|c|c|c|}
\hline \multirow{2}{*}{$\begin{array}{l}\text { Genotype } \\
\mathrm{DQ} \beta 57+\mathrm{DQ} \alpha 52\end{array}$} & \multicolumn{2}{|c|}{$\begin{array}{l}\text { Diabetic pa- } \\
\text { tients } \\
(n=102)\end{array}$} & \multicolumn{2}{|c|}{$\begin{array}{l}\text { Non-diabetic } \\
\text { subjects } \\
(n=87)\end{array}$} & \multicolumn{2}{|l|}{ Risk } \\
\hline & $n$ & Freq. & $n$ & Freq. & Relative & Absolute $^{a}$ \\
\hline $\mathrm{nD} / \mathrm{nD}+\mathrm{R} / \mathrm{R}$ & 66 & 0.65 & 6 & 0.07 & 30.7 & 101.3 \\
\hline $\mathrm{nD} / \mathrm{nD}+\mathrm{R} / \mathrm{nR}$ & 16 & 0.15 & 9 & 0.10 & 5.2 & 17.2 \\
\hline $\mathrm{nD} / \mathrm{nD}+\mathrm{nR} / \mathrm{nR}$ & 2 & 0.02 & 10 & 0.11 & 0.7 & 2.3 \\
\hline $\mathrm{n} \mathrm{D} / \mathrm{D}+\mathrm{R} / \mathrm{R}$ & 11 & 0.11 & 12 & 0.14 & 2.8 & 9.2 \\
\hline $\mathrm{nD} / \mathrm{D}+\mathrm{R} / \mathrm{nR}$ & 1 & 0.01 & 17 & 0.20 & 0.3 & 1.0 \\
\hline $\mathrm{nD} / \mathrm{D}+\mathrm{nR} / \mathrm{nR}$ & 0 & 0.00 & 16 & 0.18 & 0.1 & 0.3 \\
\hline $\mathrm{D} / \mathrm{D}+\mathrm{R} / \mathrm{R}$ & 3 & 0.03 & 6 & 0.07 & 1.6 & 5.3 \\
\hline $\mathrm{D} / \mathrm{D}+\mathrm{R} / \mathrm{nR}$ & 3 & 0.03 & 10 & 0.12 & 1.0 & 3.3 \\
\hline $\mathrm{D} / \mathrm{D}+\mathrm{nR} / \mathrm{nR}$ & 0 & 0.00 & 1 & 0.01 & 1.0 & 3.3 \\
\hline \multicolumn{7}{|l|}{$\begin{array}{l}\text { Possible } \\
\text { heterodimers }\end{array}$} \\
\hline 4 & 66 & 0.65 & 6 & 0.07 & 52.4 & 101.7 \\
\hline 2 & 27 & 0.26 & 21 & 0.24 & 6.6 & 12.8 \\
\hline 1 & 1 & 0.01 & 17 & 0.20 & 0.4 & 0.8 \\
\hline 0 & 8 & 0.08 & 43 & 0.49 & 1.0 & 1.94 \\
\hline
\end{tabular}

non-Asp 57 and DQ $\alpha \operatorname{Arg} 52$ positive had more than a 30fold relative increase in risk for Type 1 diabetes $(p<0.01)$ and the highest absolute Type 1 diabetes risk. These individuals can produce four possible "diabetogenic" heterodimers, considering both in cis and in trans combinations, while individuals heterozygous for at least one of the loci can produce only two such molecules. Those who were non-Asp 57 homozygous and heterozygous for Arg 52, as well as those who were heterozygous for Asp 57 and homozygous for Arg 52, had a slightly increased risk relative to those with the Asp 57 homozygous and nonArg 52 homozygous genotype. The absolute Type 1 diabetes risk for those individuals were similar to that for the general population. Thus, the presence of two vs one copy of both high-risk alleles permitted further discrimination in Type 1 diabetes risk than could be achieved by considering either DQ $\alpha$ or $\mathrm{DQ} \beta$ alone (Table 2). Those who are heterozygous at both loci and only have the possibility of producing one "diabetogenic" heterodimer, together with the groups remaining (i. e., homozygous for Asp 57 or non-Arg 52) that cannot form any of these molecules, had a very low Type 1 diabetes risk.

\section{Discussion}

The HLA class II alleles are recognized to be the genetic markers most highly related to Type 1 diabetes susceptibility. Among these, the DQ alleles are the ones previously shown to have the highest association with Type 1 diabetes [21, 23-27] and were used in these analyses. The typing was performed on a large number of subjects from Madrid using allele specific oligonucleotides for either the $\mathrm{DQ} \beta$ or the DQ $\alpha$ chain alleles. These individuals were selected according to a standardized international protocol [22], permitting precise estimates of the population gene frequency and genotype-specific incidence rates, and accurate comparisons between populations.
The data obtained from this evaluation confirmed that in the Spanish population, the absence of aspartic acid in position 57 of the DQ $\beta$ chain is also highly associated with Type 1 diabetes. The frequency of non-Asp 57 among the diabetic patients was in the expected range, but higher than predicted [22] based on the incidence of the disease [18]. It is likely that the absence of aspartic acid in position 57 of the $\mathrm{DQ} \beta$ chain may not entirely determine susceptibility to the disease in this population, as well as in others previously studied $[21,27,35]$, since some Type 1 diabetic patients were Asp 57 homozygotes. Interestingly, as already observed in the case of the Chinese population [35], the majority of the diabetic patients who were found to be Asp 57 homozygotes had only DQB ${ }^{*} 0301$ or 0303 alleles. These alleles were originally defined by Todd et al. [23] as "neutral" in their protective effect against Type 1 diabetes.

When we considered the effect of the alleles of the DQ $\alpha$ chain, we focused on the presence or absence of an arginine in position 52. As expected, this marker was strongly associated with Type 1 diabetes. Moreover, the genotype-specific incidence rate for Arg 52 homozygosity and non-Asp 57 homozygosity were approximately equal. However, susceptibility to the disease was not confined to this genetic marker.

The analysis of both markers together showed an even stronger association to Type 1 diabetes, as was suggested by the French group [26]. When $\mathrm{DQ} \beta$ non-Asp 57 and $\mathrm{DQ} \alpha$ Arg 52 alleles were considered in combination, the absolute risk of developing the disease was markedly increased (101 per 100,000 per year), supporting a synergistic interaction between the two markers. These doublehomozygotes were found in $65 \%$ of the diabetic patients, but only $7 \%$ of the control population, yielding a population attributable risk of $62 \%$. Thus, approximately twothirds of the incidence of Type 1 diabetes in Madrid can be explained by the presence of these two high-risk alleles. It was impressive that only $8 \%$ of all diabetic patients did not express at least one of the "diabetogenic" alleles either in the $\mathrm{DQ} \beta$ or $\mathrm{DQ} \alpha$ chain genes.

These data, therefore, provide strong evidence that a quantitative effect is promoted by both these DQ markers, since the absolute Type 1 diabetes risk varies with the possibility of generating 4,2 or 1 "diabetogenic" dimers. This is the first study to generate data of this kind, and is an excellent example of molecular epidemiology, as it offers a model for assessing the magnitude of genotype-specific effects on Type 1 diabetes risk [36]. These data are also in very good agreement with the molecular hypothesis proposed by Khalil et al. [26], in which the expression of the heterodimer consisting of a non-Asp $57 \beta$ chain together with an Arg $52 \alpha$ chain at the cell surface increased the diabetogenic effect. Although speculative, this hypothesis stands on the demonstration that these heterodimers actually exist $[37,38]$, and stresses the importance of the complete dimer rather than a single chain alone, finding strong support in the three-dimensional confirmation of the DQ molecule.

The presence of a diabetogenic DQ dimer at the cell surface does not seem to be absolutely necessary for the development of Type 1 diabetes. In fact, this dimer cannot 
be generated in $8 \%$ of the cases tested. On the contrary, these results seem to point to a dose-response effect [22, 35-36, 39] associated with these Type 1 diabetes susceptibility markers, a situation in which environmental factors or other genes must play their role as well.

These data will also serve as the basis for future studies of Spanish heritage populations. Through their migration to the New World, the Spaniards introduced new genes to the Americas and were exposed to novel environmental and cultural factors. The incidence of Type 1 diabetes varies dramatically across Spanish-heritage populations [40], with very low rates reported for Cuba and Mexico City and high rates for other Hispanic populations in the United States. Comparison of the HLA-DQ genotype distribution and genetic distance between Madrid, Mexico City and other Spanish heritage populations in the Americas will provide important new information regarding the contribution of Type 1 diabetes susceptibility genes and genetic admixture to disease risk among Hispanics and other minorities.

Acknowledgements. We wish to acknowledge the help of Drs. W.A. Rudert and R. LaPorte in the preparation of this manuscript. This work was supported in part by Fundacion Valgrande, Fondo De Investigaciones Sanitarias 89/0269, Programa Sectorial de Promocion General del Conocimento-DGICYTPM 90-0034, and by grants from the American National Institutes of Health: RO1 DK24021, RO1 AI23963, and RO1 DK42316.

\section{References}

1. Diabetes Epidemiology Research International Group (1988) Geographic patterns of childhood insulin-dependent diabetes mellitus. Diabetes 37: 1113-1119

2. LaPorte RE, Tajima N, Akerblom HK et al. (1986) Geographic differences in the risk of insulin dependent diabetes mellitus: the importance of registries. Diab Care 8 [Suppl 1]:101-107

3. Tuomilehto J, Rewers M, Reunanen A et al. (1991) Increasing trend in Type 1 (insulin-dependent) diabetes mellitus in childhood in Finland. Analysis of age, calendar time and birth cohort effects during 1965-1984. Diabetologia 34: 282-287

4. Levy-Marchal C, Papoz L, de Beaufort Cet al. (1990) Incidence of juvenile Type 1 (insulin-dependent) diabetes mellitus in France. Diabetologia 33: 465-469

5. Bruno G, Merletti F, Pisu E, Pastore G, Marengo C, Pagano G (1990) Incidence of IDDM during 1984-1986 in population aged $<30$ years. Diab Care 13: 1051-1054

6. Calori G, Gallus G, Garancini P, Repetto F, Micossi P (1990) Identification of the cohort of type 1 diabetes presenting in Lombardy in 1983-84: a validated assessment. Diab Med 7: 595-599

7. Diabetes Epidemiology Research International Study Group (1990) The epidemiology and immunogenetics of IDDM in Italian-heritage populations. Diab Metab Rev 6: 63-68

8. Joner G, Sovik O (1989) Increasing incidence of diabetes mellitus in Norwegian children 0-14 years of age 1973-1982. Diabetologia 32: 79-83

9. Dahlquist G, Blom L, Holmgren G et al. (1985) The epidemiology of diabetes in Swedish children 0-14 years - a six-year prospective study. Diabetologia 28: 802-808

10. Banatvala JE, Bryant J, Schernthaner G et al. (1985) Coxsackie $\mathrm{B}$, mumps, rubella, and cytomegalovirus specific IgM responses in patients with juvenile onset insulin-dependent diabetes mellitus in Britain, Austria and Australia. Lancet I: 1409-1411

11. Yoon JY, Ray UR (1985) Perspectives on the role of viruses in insulin-dependent diabetes. Diab Care 8 [Suppl 1]: 39-44
12. Borch-Johnsen K, Joner G, Mandrup-Poulsen T et al. (1984) Relation between breast-feeding and incidence rates of insulin-dependent diabetes mellitus. Lancet II: $1083-1086$

13. Helgason T, Jonasson MR (1985) Evidence for a food-additive as a cause of ketosis-prone diabetes. Lancet II: 716-720

14. LaPorte RE, Orchard TJ, Kuller LH et al. (1981) The Pittsburgh insulin-dependent diabetes mellitus registry: the relationship of insulin-dependent diabetes mellitus to social class. Am J Epidem 114: 379-384

15. Robinson N, Fuller JH (1985) Role of life events and difficulties in the onset of diabetes mellitus. J Psych Res 29:215-225

16. Diabetes Epidemiology Research International Study Group (1987) Preventing insulin-dependent diabetes mellitus: the environmental challenge. Br Med J 295: 479-481

17. Songini M, Muntoni S (1991) High incidence of type I diabetes in Sardinia. Lancet 337: 1047

18. Serrano-Ríos M, Moy CS, Martín Serrano R et al. (1990) Incidence of Type 1 diabetes mellitus in subjects $0-14$ years of age in the Comúnidad of Madrid, Spain. Diabetologia 33: 422-424

19. Cavalli-Sforza LL, Piazza A, Menozzi P, Mountain J (1988) Reconstruction of human evolution: bringing together genetic, archaelogical and linguistic data. Proc Natl Acad Sci USA 85: 6002-6006

20. Contu L, Carcassi C, Trucco M (1991) Diabetes susceptibility in Sardinia. Lancet 338: 65

21. Carcassi C, Trucco G, Trucco M, Contu L (1991) A new HLADR2 extended haplotype is involved in IDDM susceptibility. Hum Immunol 31: 159-165

22. Dorman J, LaPorte R, Stone R, Trucco M (1990) Worldwide differences in the incidence of Type I diabetes are associated with amino acid variation at position 57 of the HLA-DQ beta chain. Proc Natl Acad Sci USA 87: 7370-7374

23. Todd JA, Bell JL, McDevitt HO (1987) HLA-DQ beta gene contributes to susceptibility and resistance to insulin-dependent diabetes mellitus. Nature 329: 559-604

24. Morel P, Dorman J, Todd J, McDevitt H, Trucco M (1988) Aspartic acid at position 57 of the HLA DQ-beta chain protects against type I diabetes: a family study. Proc Natl Acad Sci USA 85: $8111-8115$

25. Baisch JM, Weeks T, Giles R, Hoover M, Stastny P, Capra JD (1990) Analysis of HLA-DQ genotypes and susceptibility in insulin-dependent diabetes mellitus. N Engl J Med 322: 1836-1841

26. Khalil I, d'Auriol L, Gobet M et al. (1990) A combination of HLA-DQ $\beta$ Asp 57-negative and HLA-DQ $\alpha$ Arg 52 confers susceptibility to insulin-dependent diabetes mellitus. J Clin Invest 85: $1315-1319$

27. Rønningen KS, Gjertsen HA, Iwe T, Spurkland A, Hansen T, Thorsby E (1991) Particular HLA-DQ alpha beta heterodimer associated with IDDM susceptibility in both DR4-DQw4 Japanese and DR4-DQw8/DRw8-DQw4 whites. Diabetes 40: $759-763$

28. WHO DIAMOND Project Group (1990) WHO multinational project for childhood diabetes. Diab Care 13: 1062-1068

29. Marsh SG, Bodmer JG (1991) HLA Class II nucleotide sequences. Hum Immunol 31: 207-226

30. Maniatis TM, Fritsch EF, Sambrook J (1982) Molecular Cloning. A Laboratory Manual. Cold Spring Harbor Laboratory, New York

31. Saiki RK, Gelfand DH, Stoffel S et al. (1988) Primer-directed enzymatic amplification of DNA with a thermostable DNA polymerase. Science 239: 487-491

32. Trucco G, Fritsch R, Giorda R, Trucco M (1989) Rapid detection of IDDM susceptibility, using amino acid 57 of the HLA-DQ beta chain as a marker. Diabetes 38: 1617-1619

33. Bodmer JG, Marsh SG, Albert ED et al. (1991) Nomenclature for factors of the HLA system, 1990. Hum Immunol 31: 195-206

34. Haldane JBS (1956) The estimation and significance of the logarithm of a ratio of frequencies. Ann Hum Genet 20:309-313

35. Bao MZ, Wang JX, Dorman JS, Trucco M (1989) HLA-DQ beta non-Asp 57 allele and incidence of Diabetes in China and the U.S.A. Lancet II:297 
36. Dorman J, LaPorte R, Trucco M (1991) Genes and environment. In: Tait B, Harrison L (eds) The genetics of diabetes. Balliere's Clinical Endocrinology and Metabolism, Vol. 5. Bailliere Tindall, p 229

37. Charron DJ, Lotteau V, Turmel P (1984) Hybrid HLA-DC antigens provide molecular evidence for gene trans-complementation. Nature 312: 157-159

38. Kwok WW, Thurtle P, Nepom GT (1989) A genetically controlled pairing anomaly between HLA-DQ alpha and HLA-DQ beta chains. J Immunol 143: 3598-3601

39. Trucco M (1990) The genetic susceptibility to Type I diabetes: clinical and immunogenetic studies. Int Diab Fed Bull 35: 31
40. Diabetes Epidemiology Research International Group (1989) Evaluation of epidemiology and immunogenetics of IDDM in Spanish- and Portuguese-heritage registeries. A key to understanding the etiology of IDDM? Diab Care 12: 487-493

Received: 25 October 1991

and in revised form: 7 February 1992

Dr. M. Serrano-Rios

Cea Bermudez 66, $5^{\circ}-\mathrm{G}$

E-28003 Madrid

Spain 